\title{
Research progress on ecological restoration of landscape water
}

\author{
Zhe Zhang $^{1 *}$, and Yibing Feng ${ }^{2}$ \\ ${ }^{1}$ Cological Technology and Engineering, Shanghai Institute of Technology, Shanghai, 201418, China \\ ${ }^{2}$ Cological Technology and Engineering, Shanghai Institute of Technology, Shanghai, 201418, China
}

\begin{abstract}
With the rapid development of my country's economy and the advancement of urban-rural integration, the urban population has increased sharply, people's basic survival problems have been solved, and more and more attention has been paid to landscapes and landscape water. The sources of water pollution were described, the effects and characteristics of water restoration methods were analyzed and compared, and suggestions were made for landscape water restoration.Immobilization technology has great advantages in ecological restoration of landscape water bodies, with strong environmental adaptability and high tolerance to environmental conditions.
\end{abstract}

\section{Introduction}

With the rapid development of my country's economy and the advancement of urban-rural integration, the urban population has increased sharply, and people' $\mathrm{s}$ basic survival problems have been solved. People' $s$ consideration of quality of life has begun to increase, and more attention will be paid to the high-quality living environment. People pay more and more attention to landscape water ${ }^{[1]}$. The landscape water body is of great significance to the design and planning of the landscape. It can increase the level of the landscape and the changes of virtual and real, divide the space, and modify the surrounding environment. It can be the core of the landscape or the finishing touch. It is a rare complex with aesthetic feeling, ecological benefit and economic value at the same time.

Landscape water have the characteristics of poor self-purification, poor fluidity and semi-enclosed water, which are easy to precipitate and accumulate pollutants. There are also characteristics of large flow of people around them, making it easier to produce and discover water pollution problems. According to related studies, about $93 \%$ of the park landscape water in the country have varying degrees of pollution, and the water are seriously eutrophication ${ }^{[2]}$. Immobilized materials have the characteristics of strong adaptability, high purification efficiency and easy solid-liquid separation. It can increase the density of the fungus, prevent the loss of the fungus, enhance the protection of the functional fungus, and prevent the water body from being polluted by the functional fungus.

\section{Pollution status of landscape water}

The pollution problem of landscape water is becoming more and more serious. At present, the pollution of landscape water mainly comes from the following aspects:

\subsection{Landscape water body water source}

The water sources of landscape water mainly come from river water, groundwater and tap water ${ }^{[3]}$. Pollutants in rivers and lakes penetrate into the ground through osmosis, thereby polluting groundwater. Many landscape water are directly connected to groundwater. In recent years, the country has stepped up its efforts to control rivers and lakes, but there are still some areas and indicators that have not reached the national standards for landscape water, which has caused landscape water to be polluted from the source.

\subsection{Unreasonable landscape water design}

Most of the landscape water are artificial water. The main characteristics are closed water, shallow water levels, poor fluidity or completely standing still, and the flow direction of some places is messy, which is easy to form dead corners, and there is not enough power to take away pollutants. Lead to the accumulation of pollutants, which in turn causes the overall water quality to deteriorate. In addition, most of the rivers and lakes in cities have hardened riverbeds and lake bottoms to facilitate management and development and utilization, destroying the habitat of aquatic organisms in the water body, destroying the ecological function of the water body, and losing the water body's self-purification ability.

\subsection{Impact of external source pollution}

Some landscape water are directly connected to the

*Corresponding author:186111130@mail.sit.edu.cn 
urban water network, and the pollution sources are mainly caused by the following points: the leakage of sewage along the water network river, the confluence of rain and sewage, the mixed connection and private sewage outlets, etc.; the hidden trenches and sewage interception pipelines set along the banks, Due to disrepair and clogging, sewage leaks, overflows and even directly drains into the water network river; the water body has insufficient self-purification capacity, and the garbage and sludge at the bottom mainly come from the corrupt deposits of microorganisms; the species of aquatic plants are single and thriving. Lack of control, the parts floating on the water are easy to hook garbage, and are not easy to salvage, which affects the overall aesthetic effect of the landscape water body; the water body has insufficient power and the water velocity is slow, and there is not enough power to take away the pollutants and accumulate and deposit in the water body; The slopes along the water body are too steep, and part of the soil is exposed, which is easy to wash into the water body.

\subsection{The impact of algae flooding}

Because the spores of algae are light in weight, they can be spread through air currents, and when nutrients are sufficient, they grow and reproduce extremely fast. During their growth and reproduction, they need to consume a lot of oxygen in the water body, reduce the content of dissolved oxygen in the water body, and form Black and smelly water. When the algae is severely flooded, it covers the water body, which affects the aquatic plants to absorb sunlight for photosynthesis, and also causes the aquatic organisms to suffocate due to lack of oxygen.

\subsection{The influence of ornamental fish}

In order to make the landscape water full of vigor and vitality, most of the water are stocked with ornamental fishes. The food fed by tourists and the excrement of fish will increase the content of organic matter in the water body. Once these pollutants exceed the self-purification capacity of the water body, the water body will turn black and smelly, the dissolved oxygen content will decrease, and the water body will become hypoxic. The conditions have led to a large number of deaths of fish and shrimp, and these decaying aquatic animals will further increase the degree of eutrophication of the water body, putting the water body in a vicious circle.

\section{Ecological restoration methods for landscape water at home and abroad}

Regarding the treatment of landscape water pollution, based on the principle of "controlling external pollutants and reducing endogenous nutrient load" at home and abroad $^{[1]}$, a variety of pollution treatment technologies have been produced and applied in engineering. For heavily polluted water with high pollutant concentrations and poor habitats that are not suitable for biological survival and growth, physical and chemical methods are mainly adopted; for moderately polluted water or water with less pollution, biological methods become more effective, more economical and more economical. Environmentally friendly governance methods. Biological law improves the treatment capacity of pollutants by improving and strengthening the ecosystem of the water body, thereby purifying the water body. Mainly divided into microbial remediation method and phytoremediation method.

\subsection{Phytoremediation}

Phytoremediation is to introduce fine plant species into the degraded aquatic ecosystem to promote the restoration of the water ecosystem ${ }^{[4]}$. Through the growth and assimilation of aquatic plants, it absorbs nutrients in the water body to achieve the purpose of purifying the water body. The aquatic plants used for landscape water restoration include wet plants, emergent plants, floating-leaf plants, floating plants and submerged plants. The phytoremediation method has the advantages of low cost and good ecological benefits. It can provide habitat and foraging places for aquatic animals and birds. It is also one of the components of the water landscape, coupled with a reasonable combination to increase the ornamental. In practical applications, the treatment of ecological floating islands and constructed wetlands is more common. The ecological floating island technology uses floating island plants to absorb and adsorb nitrogen and phosphorus; secrete biological enzymes to promote the decomposition of organic matter in the water; block sunlight to inhibit the photosynthesis of algae ${ }^{[5]}$. Zheng $\mathrm{Jili}^{[6]}$ and others used ecological floating islands to purify the water body of Changzhou Zaogang River, which has a good removal effect on ammonia nitrogen and total phosphorus. Liu Yushuang et al. ${ }^{[7]}$ used a combination of three emergent plants (aquaticum, water hyacinth, and calamus) as floating island plants, which had a significant effect on the removal of ammonia nitrogen and total nitrogen in the water body under aeration. Constructed wetland uses matrix, plants and microorganisms to repair water and remove pollutants. Chen Taife ${ }^{[8]}$ and others used OAO aquatic vegetable artificial wetland to treat rural non-point source pollution, and the removal rate of ammonia nitrogen and nitrate nitrogen at the optimal hydraulic load of $0.3 \mathrm{~m}^{3} /\left(\mathrm{m}^{2} \cdot \mathrm{d}\right)$ was above $70 \%$. Elfanssi et al. ${ }^{[9]}$ used constructed wetlands to purify eutrophic water and found that the wetland system has a higher removal rate of ammonia nitrogen and total nitrogen.

\subsection{Microbial remediation method}

The microbial remediation method mainly uses naturally occurring or easily cultivated microorganisms. Within the control range, through the degradation and transformation of microorganisms, toxic and harmful substances are transformed into non-toxic and harmless substances, thereby improving and repairing the 
pollution of water ${ }^{[10]}$. The microbial remediation method involves the screening, cultivation, domestication and compounding of microorganisms, and the investment in preliminary research and experiments is relatively large.

Table 1. Comparison of different immobilization methods

\begin{tabular}{ccccc}
\hline Immobilization method & Operational & Binding power & Microbial activity & Cost \\
\hline Adsorption method & Easy & Weaker & High activity & Inexpensive \\
Embedding method & Easier & Powerful & High activity & Medium \\
Covalency & Difficult & Powerful & Weaker activity & Medium \\
Crosslinking method & Difficult & Powerful & Weaker activity & Expensive \\
\hline
\end{tabular}

Microbial remediation methods can be divided into the following categories: biofilm method, inoculant method, protozoan activation method, and immobilized microorganism method. In practical applications, the method of dosing inoculants started early and is relatively common, mainly adding functional inoculants to degrade pollutants in the water body, such as nitrifying bacteria, denitrifying bacteria, and lactic acid bacteria. Miao Xinxin et al. ${ }^{[11]}$ used Bacillus subtilis, which has strong nitrification and denitrification effects, to treat college landscape waters. Planting the bacteria in low-carbon nitrogen than landscape waters has a faster removal efficiency and a better effect. Gan et al. ${ }^{[12]}$ used polyurethane foam as a carrier to immobilize microorganisms and studied its denitrification ability in micro-polluted waters. Nitrate was completely removed in about 5 hours. In recent years, the indigenous microorganism activation method and the immobilized microorganism method have also been developed and applied. The indigenous microorganism activation method mainly activates the proliferation and proliferation of native beneficial bacteria by adding specific nutrients, biological enzymes, electrons or cometabolism substrates to the water body, and gives full play to the ability of indigenous microorganisms to degrade pollutants, so as to achieve water body restoration The purpose of ${ }^{[13]}$. The immobilized microorganism method is to make biological materials by immobilizing functional bacteria groups on certain carriers to increase the density of the bacteria, prevent the loss of the bacteria, and enhance the protection of the functional bacteria. It is easy to separate solid and liquid and prevent Functional bacterial agents cause secondary pollution to water. Immobilization methods mainly include adsorption method, embedding method, cross-linking method and covalent method, as shown in Table 1. There are many new immobilization methods and composite immobilization methods.

The choice of immobilized microbial carrier is critical to the effect of immobilization, and different immobilization methods have different requirements for carrier materials. The carrier materials can be divided into the following five categories: inorganic carriers, modified inorganic carriers, natural organic carriers, synthetic organic carriers and composite carriers. Commonly used immobilized carriers are shown in Table 2.

Table 2 Common carrier for immobilized microorganism

\begin{tabular}{|c|c|c|c|c|}
\hline $\begin{array}{c}\text { Inorganic } \\
\text { carrier }\end{array}$ & $\begin{array}{c}\text { Modified inorganic } \\
\text { carrier }\end{array}$ & $\begin{array}{l}\text { Natural organic } \\
\text { carrier }\end{array}$ & $\begin{array}{c}\text { Synthetic organic } \\
\text { carrier }\end{array}$ & Composite carrier \\
\hline Zeolite & Molecular sieve & Carrageenan & Silica gel & $\mathrm{PVA}+\mathrm{SA}$ \\
\hline diatomite & Carbon nanotubes & $\begin{array}{l}\text { Sodium Alginate } \\
\text { (SA) }\end{array}$ & Polyurethane & Polyurethane + Zeolite \\
\hline Volcanic rock & $\begin{array}{l}\text { Activated carbon } \\
\text { (AC) }\end{array}$ & Agar & $\begin{array}{c}\text { Polyvinyl Alcohol } \\
\text { (PVA) }\end{array}$ & $\mathrm{SA}+\mathrm{AC}$ \\
\hline Quartz sand & Porous ceramsite & Cellulose & Polyhydroxybutyrate & \\
\hline
\end{tabular}

The natural inorganic carrier has stable properties, high mechanical strength, good mass transfer performance, no harm to microorganisms, and low price. Through the modification treatment, the specific surface area of the carrier is increased and the ability to immobilize microorganisms is increased. The natural organic carrier is generally non-toxic, good in mass transfer performance, and has a high fixed amount of microorganisms. It can be used as a carbon source for microorganisms (such as cellulose) to promote denitrification and denitrification. The synthetic organic carrier has good chemical stability, relatively large amount of immobilized microorganisms, 
and low price. However, part of the immobilization process involves chemical reactions and has a certain toxic effect on microorganisms. The composite carrier is the combination of multiple carriers to improve the defects of a single carrier and obtain an ideal carrier, which is widely used in immobilized materials.

\section{Fixing material repair method}

\subsection{Nitrogen-containing wastewater}

The harm of ammonia nitrogen to aquatic organisms is mainly manifested in the effect of non-ionic ammonia on the enzyme hydrolysis reaction and membrane stability of organisms, and it also has a greater impact on the biochemical indicators and growth status of aquatic organisms. Nitrifying bacteria and denitrifying bacteria can degrade the excessive ammonia nitrogen and nitrate nitrogen in the water body, thereby reducing the nitrogen content in the water body.

Li Fuyu ${ }^{[14]}$ obtained many different kinds of bacteria by separating and purifying the fungi in the water body of Liangtan River, including nitrifying bacteria, light and bacteria, yeast and phosphorous accumulating bacteria. These strains are screened and compounded, and fixed into biological materials. The removal rate of chemical oxygen demand and ammonia nitrogen is about 3 times that of the unfixed compound bacterial agent.

Dong et al. [15] used suspended polyurethane to immobilize nitrifying bacteria to treat low-concentration ammonia nitrogen wastewater, and evaluated the impact of environmental factors on the removal of low-concentration ammonia nitrogen, such as temperature, dissolved oxygen concentration, and $\mathrm{pH}$. The residence time is controlled at $30 \mathrm{~min}$. Continuous treatment of ammonia nitrogen with a concentration of 1 $\mathrm{mg} / \mathrm{L}$ has a removal rate of up to $80 \%$, showing the broad application prospects of immobilized microorganisms to lightly polluted water sources.

After long-term domestication, Yin $\mathrm{Li}$ et al. ${ }^{[16]}$ optimized the cultivation of functional bacteria such as bacillus, nitrifying bacteria, and lactic acid bacteria. After immobilization, the initial concentration of $37 \mathrm{mg} / \mathrm{L}$ ammonia nitrogen, $2.44 \mathrm{mg} / \mathrm{L}$ total nitrogen, The chemical oxygen demand of $800 \mathrm{mg} / \mathrm{L}$ has an excellent removal effect, and the removal rates are $100 \%, 45.49 \%$, and $93.38 \%$, respectively.

Cao GM et al. ${ }^{[17]}$ used polyvinyl alcohol as a carrier and immobilized nitrifying bacteria and denitrifying bacteria using the embedding method. The prepared biological material has strong resistance to shock loads and can achieve nitrification in the same reaction space. Denitrification.

\subsection{Wastewater containing organic matter}

Wang Qishan et al. ${ }^{[18]}$ screened out p-nitrophenol degrading bacteria from activated sludge, and immobilized them to improve the degradation rate of p-nitrophenol in wastewater. The results show that when the temperature is $35^{\circ} \mathrm{C}$, the $\mathrm{pH}$ is $9-12$, and the p-nitrophenol concentration is less than or equal to 150 $\mathrm{mg} / \mathrm{L}$, the removal rate of the embedded particles remains above $80 \%$.

AM Anselmo et al. ${ }^{[19]}$ used polyurethane as the main carrier to immobilize Fusarium lanuginosa, and carried out continuous phenol degradation experiments in the reactor. When the phenol influent concentration was 1000 $\mathrm{mg} / \mathrm{L}$, the microbial materials could basically be removed completely and continuously. It has been running stably for four months, and it is found through the breath test experiment that the immobilized microorganisms still have high activity.

$\mathrm{Wu}$ Fangfang et al. ${ }^{[20]}$ put polyvinyl alcohol-embedded high-efficiency phenol-degrading strains into a batch activated sludge reactor to study its effect on the treatment of gas washing and cold wastewater. Experiments show that the fixed strain has a removal rate of $94 \%$ for wastewater with a phenol concentration of $5000 \mathrm{mg} / \mathrm{L}$ within 10 days, while the free strain can only treat wastewater with a phenol concentration of $\leqslant 1500 \mathrm{mg} / \mathrm{L}$. It shows that the treatment of phenol-containing wastewater by immobilized microorganisms is more efficient and has a wider range of applications.

The circulating water of oil refining contains a large amount of organic matter such as hydrocarbons. Wang Yongjun ${ }^{[21]}$ and others made polyvinyl alcohol, sodium alginate, and $\mathrm{Fe} 3 \mathrm{O} 4$ into composite carriers to embed crude oil degrading bacteria to treat oily wastewater. It is shown that the removal rate of biological materials for simulated wastewater with a diesel mass concentration of $60 \mathrm{mg} / \mathrm{L}$ can reach more than $99 \%$ in 72 hours. And after diesel domestication, biological materials can reach $99 \%$ of oily wastewater under the same conditions in 40 hours.

Ding Shaolan et al. ${ }^{[22]}$ used polyvinyl alcohol to embed white rot fungi to decolorize the dye wastewater, and the results showed that the dye wastewater has a significant decolorization effect under relatively easy to achieve conditions.

\section{Conclusion}

The application of ecological restoration in the restoration of landscape water in recent years is briefly summarized. The ecological restoration of landscape water is one of the current governance methods with little impact on the environment and has broad application prospects. In the follow-up research, it is also necessary to explore treatment methods with strong removal ability of landscape water pollutants and good environmental adaptability. The inoculum and carbon source can be compounded, and the compounded mixture can be fixed to prepare immobilized materials, promote the removal of pollutants by the inoculum, and provide a carbon source for nitrification and denitrification reactions, making the immobilization technology more effective There are broader applications in ecological restoration of landscape water. 


\section{References}

1. Tan, H F.(2008) Research on Urban Landscape Water Treatment Technology (Taking Nanming River as an Example). Guizhou Normal University.

2. Ding, L. Shen, Y L. Huang, Y. (2005) Rehabilitation technology and development status of water bodies in the park. Journal of Suzhou University of Science and Technology (Engineering Technology Edition), 18(002): 48-52.

3. Li, P P. (2020) Analysis of Water Quality Control Strategy and Application of Landscape Water Body . Housing and Real Estate , 24: 60-61.

4. Li, Ming. Liu, D Q. Shen, S D. et al. (2007) Research progress of ecological restoration technology for eutrophic lakes in China. Soil and Water Conservation Research , 05: 378-380+398.

5. Liu, J J. Peng, J Y. Wu Q. (2014) Current Status and Prospects of Research on Ecological Floating Island Technology . Hunan Agricultural Sciences. 15: 47-49.

6. Zhen, J L. Pan, H Z. Zhuang, H Q. (2018) Harnessing and Ecological Restoration of the Black and Smelly Channel of the Zaogang River in Changzhou . China Water \& Wastewater .22: 90-95.

7. Liu, Y S. Liu, J. Zhao, H. et al. (2018)Application of solar energy micro-power ecological floating island technology in water body restoration. Shandong Chemical Industry . 47: 137-137+143.

8. Chen, T F. Han, Q. Zhai, Z D. et al. (2018) Removal effect of OAO aquatic vegetable constructed wetland process on nitrogen and phosphorus in rural sewage discharged in disorder . Water purification technology . 11: 120-128.

9. Saloua, Elfanssi, Naaila, et al. (2017) Phytoremediation of domestic wastewater using a hybrid constructed wetland in mountainous rural area. International Journal of Phytoremediation. 20(1).

10. Li, T. (2013)Preparation of Polyvinyl Alcohol Composite Carrier and Study on Immobilization of Highly Efficient Degrading Bacteria . South China University of Technology .

11. Miu, X X. Zhang, L. Tan, S M. et al. (2013) Carbon source and denitrifying bacillus enhance the biological denitrification of landscape water bodies with low $\mathrm{C} / \mathrm{N}$ ratio . Journal of Environmental Engineering . 05: 1661-1664.
12. Gan Y, Zhao Q, Ye Z. (2019) Denitrification performance and microbial diversity of immobilized bacterial consortium treating nitrate micro-polluted water[J]. Bioresource technology. 281: 351.

13. Li, X. Lin, F K. Xu, Z. (2009) Research on Application of Compound Enzyme Biological Accelerator in Remediation of Polluted River . Water purification technology . 028(004): 38-41.

14. Li, F Y. (2011) Research on Treatment of Liangtan River Water Body by Immobilized Compound Microorganism Technology . Chongqing University .

15. Dong, Y. Zhang, Z. Jin, Y. et al. (2011) Nitrification performance of nitrifying bacteria immobilized in waterborne polyurethane at low ammonia nitrogen concentrations. Journal of Environmental ences,03: 366-371.

16. Lin, L. Zhang, P H. Chen, W Y. et al. (2018) Study on Purification of Black and Odorous Water Body of Keng Pond by Immobilized Microorganism Technology . Water treatment technology . 044(002): 105-108.

17. Cao, G M. Zhao, Q X. Sun, X B. et al. (2002) Characterization of nitrifying and denitrifying bacteria coimmobilized in PVA and kinetics model of biological nitrogen removal by coimmobilized cells. Enzyme \& Microbial Technology. 30(1): 49-55.

18. Wang, Q S. Han, X. Yu, C L. et al. (2018) Study on the degradation of p-nitrophenol wastewater by CMC-bentonite immobilized microorganism . Water treatment technology . 318(07): 67-70+87.

19. Anselmo, A M. Novais, J M. (1992) Degradation of Phenol by Immobilized Mycelium of Fusarium Flocciferum in Continuous Culture. Water Science and Technology, 1992.

20. Wu, F F. Lin, H. Qiu, L F. et al. (2018) Experimental Study on PVA-embedded Trichosporium TX1 in Treating Phenolic Wastewater. Coal Science and Technology . 522(05): 217-223.

21. Wang, Y J. Fu, W Q. Xue, P. (2017)Degradation of trace oil in water using magnetic immobilized microorganisms. chemical engineering. 45(009): 7-12.

22. Ding, S L. Chen, X T. Bai, X Y. (2014) Study on the Treatment of Dye Wastewater by Immobilized White Rot Fungi . 16-19. 